Revista Pax Domini é licenciada sob uma Licença Creative Commons.

\title{
E FORMOU O SENHOR DEUS O HOMEM E O INCONSCIENTE
}

Sergio Gil*

\begin{abstract}
Resumo
A proposta deste trabalho está baseada na análise, com auxílio das ciências humanas, dos três primeiros capítulos do texto bíblico em Gênesis, advindos da literatura mítica hebraica, sobre a narrativa psicodinâmica da criação do homem, e de tudo o que há. São abordadas questões sobre a "queda" do homem, e o consequente "exílio", e a relação entre o Criador e criação. Para tanto, são contemplados os olhares da teologia, da história das religiões, e dos conceitos psicanalíticos, utilizados para abordagem das motivações e propósitos intrínsecos no texto, em relação ao homem, assim como seus desejos, perversões, conflitos, culpa, e sentimentos de perda. A perspectiva que motiva este trabalho se dá em aprofundamento de tais acontecimentos em narrativa, como mecanismos utilizados pelo próprio homem em tentativa de redução da ansiedade inerente. A narrativa mesopotâmica ajudaria na compreensão do crescimento psíquico da humanidade diante do enfrentamento dos problemas existentes no mundo.
\end{abstract}

Palavras-chave: Gênesis. Conflito. Perversão. Culpa.

\begin{abstract}
The aim of this work is based on the analysis, with the aid of the human sciences, the first three chapters of the biblical text in Genesis, from the mythical literature, Hebrew on the narrative Psychodynamics the creation of man, and of all that is. Are addressed questions about the "fall" of man, and the consequent "exile", and the relationship between the creator and creation. To do so, are referred to the looks of theology, history of religions, and of psychoanalytic concepts, used for tackling the motivations and intrinsic purposes in the text in relation to man, as well as their desires, perversions, conflict, guilt, and feelings of loss. The prospect that motivates this work in deepening of such events in narrative, as mechanisms used by the man himself in an attempt to reduce the anxiety. The Mesopotamian narrative would help in understanding the psychological growth of humanity before the confrontation of the problems in the world.
\end{abstract}

Key words: Genesis. Conflict. Perversion. Fault

* Sergio P. Gil de Alcantara é psicanalista (CEPTEP), mestre em ciências das religiões (PPGCR/UNIDA), especialista em ensino escolar religioso (ESAB), bacharel em sociologia (UFF), bacharel em teologia (EST) com extensão em filosofia (CECIERJ). E-mail: prsergiogil@hotmail.com

Revista Pax Domini | Faculdade Boas Novas | v. 2 | p. 58 - 72 | mar. 2017 


\section{INTRODUÇÃO}

Um dos mitos sobre a criação de tudo o que há, encontra-se descrito no livro

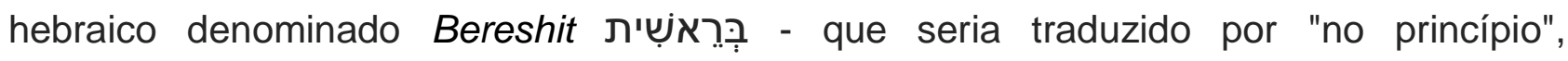
pertencente à composição literária conhecida por Torah, ou o Pentateuco. Trata-se de uma perspectiva doxa hebraica da criação do mundo, e tudo o que há, e das origens do povo hebreu. ${ }^{1}$

O primeiro livro da Bíblia cristã coincide com Bereshit da Torah. No entanto, o mesmo livro passa a ser denominado por Gênesis, da palavra grega $\Gamma \varepsilon ́ v \varepsilon \sigma / \zeta$, traduzida por "origem", "nascimento", "criação", localizando-se em compêndio de outros quatro livros, ambos conhecidos como Pentateuco. O nome Gênesis seria aplicado pela Septuaginta, que fora um trabalho realizado por setenta e dois anciãos judeus de culturalidade grega, a fim de traduzir a Torah para a língua grega. Ocorrera entre os séculos III e I a. C. ${ }^{2}$

Embora a teologia ortodoxa pronuncie a autoria do livro Gênesis a Moisés (+ ou 1450 a. C.), o qual seria o libertador do povo judeu do domínio egípcio, que ocorrera por volta de 1600 a. C., existem várias pesquisas que contradiriam essa autoria, propondo origens literárias de hipóteses documentárias, fragmentárias e complementares, levandose em conta fontes autorais denominadas como javista, eloísta, deuteronomista, e sacerdotal. $^{3}$

A motivação para o surgimento de hipóteses de fontes autorais, deu-se por atentas análises hermenêuticas do texto que constatariam repetições de eventos sob interpretações diferenciadas em textos bem próximos, no mesmo livro, como por exemplo, a origem do homem no capítulo 1 diz "façamos o homem", e no capítulo 2 diz "Deus fez o homem". No primeiro capítulo, a fonte autoral seria eloísta (Elohim - Deus poderoso tanto quanto, vários deuses), e do capítulo dois, seria javista (Yahweh - Deus único). Outra questão surgida, seria a impossibilidade de Moisés descrever a narrativa de sua própria morte. ${ }^{4}$

\footnotetext{
${ }^{1}$ WALTON, John H. Comentário bíblico Atos. Antigo testamento. Belo Horizonte: Atos, 2003, p. 21.

2 Ibidem, p. 22-23.

${ }^{3}$ PURY, Albert (Org.). O Pentateuco em questão. As origens e a composição dos cinco primeiros livros da Bíblia à luz das pesquisas recentes. Petrópolis: Vozes, 2002, p. 23-30.

${ }^{4}$ PURY, 2002, p. 18-20
}

Revista Pax Domini | Faculdade Boas Novas | v. 2 | p. 58 - 72 | mar. 2017 
A hipótese da fontes autorais ${ }^{5}$ teria como base redações que seriam construídas em diferentes épocas, sendo a Javista, compreendida no século IX a. C., a Eloísta, no século VIII a. C., a Deuteronomista, no século VII, e a fonte Sacerdotal, século V a. C. No entanto, ambas as construções autorais salientariam a questão da criação da humanidade por um ser inigualável, bem como a sua incapacidade humana em lidar com aquilo que Ihe seria instruído como lei, e a realização de seus próprios desejos. O conflito humano perpassaria por aquilo que quer, que pode, e o que deve realizar.

Desta feita, este trabalho salientará o texto hebraico em sua passagem sobre a criação, mas com alguns comparativos a partir de outros escritos babilônicos e egípcios. As devidas traduções destes textos são de responsabilidade dos próprios autores das fontes bibliográficas, devidamente citadas.

\section{A CRIAÇÃO EM GENESIS}

Para expressar um evento referencial do início de todas as coisas, seriam descritos em textos egípcios, sumerianos, babilônicos, persas e indianos, considerando-se um período, que no livro de Gênesis ficaria pontuado em sete dias. Até mesmo sobre a ideia dos sete dias, fluiriam interpretações de que a afirmação poderia expressar ao invés de realmente dias, meses, anos, séculos, ou até mesmo, milênios. Seria a expressão de tempo. O relato da criação iniciaria com a criação dos céus e a terra a partir do nada, ou das águas primordiais, trazendo uma ideia de potencialidade de um ser absoluto. O Espírito de Deus, cujo poder cria coisas de onde nunca existiram ou existiriam.

\footnotetext{
Alguns hermeneutas traduziram uma expressão como um vento sobrenatural ou impetuoso [...] que tem um paralelo no Enuma Elish babilônico. Nesse texto, o deus do céu, Anu, cria os quatro ventos que agitam as profundezas e sua deusa, Tiamat. ${ }^{6}$
}

Depois disto o livro hebraico descreve a transformação, em seis dias, do caos ao estado de ordem que culmina com a criação dos humanos à sua própria imagem. No primeiro dia a luz seria separada da escuridão. A criação da luz seria acompanhada com qualificações reguladoras do tempo, e o firmamento seria considerado como o mecanismo

\footnotetext{
${ }^{5}$ Ibidem, p. 31-34

${ }^{6}$ WALTON, 2003, p. 27
}

Revista Pax Domini | Faculdade Boas Novas | v. 2 | p. 58 - 72 | mar. 2017 
controlador da luz do sol. "A Criação propriamente dita, ou seja, a organização do "caos" (tôhú wâ bôhû), é efetuada pelo poder de palavra de Deus. Ele diz: "Haja luz, e houve luz $(1: 3){ }^{7}$

Outro importante registro da criação sob forma de poema cosmogônico denominado Enuma Elish da religião acadiana unificaria aos escritos sobre a criação do homem sumeriana. A atenção seria para a totalidade aquática com uma massa de água doce e outra salgada, e a divisão da terra à flutuar. 8 "No épico babilônico da criação, Enuma Elish, a deusa que representava esse oceano cósmico, Tiamat, é dividida em duas por Marduk para formar as a águas acima do firmamento e as águas que ficavam debaixo". 9

No segundo dia, seria criado o firmamento. Ao terceiro dia a separação entre a terra e os mares, sendo que a terra seria feita frutífera com ervas, plantas, e árvores. No quarto dia, seriam separadas a luz e a escuridão, possibilitando a marcação de dias, estações e anos. Dois grandes luminares seriam criados, uma maior e outro menor, com entendimento, o sol e a lua, no entanto, não poderiam ser expressos em literatura hebraica pois seriam nomes de divindades de outros povos vizinhos à Israel. "No prólogo de um tratado astrológico dos sumérios, os deuses principais, An, Enlil e Enki, posicionaram a lua e a estrelas a fim de determinar dias, meses e presságios"

O funcionamento do cosmos era muito mais importante as pessoas do mundo antigo do que sua forma física ou composição química. Elas descreviam o que viam, e o mais importante, aquilo que experimentavam do mundo criado por Deus. ${ }^{10}$

No quinto dia, o mar se encheria de criaturas vivas. Já no sexto dia, seriam criados os seres viventes na terra e nos céus. Criaturas das mais diversas espécies, domésticas, e selvagens.

No hino babilônico a Shamash, o deus sol recebe louvor e honra até mesmo dos piores grupos. Incluídos na lista estão os terríveis monstros do mar [...] Há uma submissão total de todas as criaturas para com Shamash, exatamente como [...] todas as criaturas feitas por Yahweh estão submissas a Ele.

\footnotetext{
${ }^{7}$ ELIADE, Mircea. História das crenças e das ideias religiosas I. Da idade da pedra aos ministérios de Elêusis. Rio de Janeiro: Zahar, 2010, p. 163.

${ }^{8}$ ELIADE, 2010, p. 77.

${ }^{9}$ WATSON, 2003, p. 27.

${ }^{10}$ Ibidem, p. 27-28.
}

Revista Pax Domini | Faculdade Boas Novas | v. 2 | p. 58 - 72 | mar. 2017 
O sexto dia, em especial, a humanidade seria criada com a incumbência de multiplicação da espécie, e o domínio sobre os animais, dados também à multiplicação, segundo suas espécies. O sétimo dia seria santificado como um dia de descanso. Em narrativa semelhante, os escritos egípcios mencionariam o mesmo episódio relacionando seus deuses. Já com relação aos deuses sumerianos e babilônicos, o trabalho da criação seria tarefa divina, mas a manutenção de tudo o que há, passaria a ser humana, tendo os deuses o merecido descanso. "No relato egípcio da criação, em Mênfis, o deus criador Ptah descansa, após terminar sua obra. A criação dos humanos pelos deuses da Mesopotâmia também é acompanhada de descanso". ${ }^{11}$

A criação do mundo, segundo os escritos babilônicos, teria por motivação o próprio deleite e apreciação dos deuses, onde o surgimento do homem seria uma ideia de última hora, pois os deuses precisariam de escravos para suprirem a comodidade de vida. Esta ideia seria oposta às narrativas bíblicas. Mas, como seria a formação deste ser humano que herdaria o usufruto de tudo o que há, na perspectiva hebraica, entretanto também teria a incumbência de administrar e dominar sobre as outras espécies. Não seria este ser, dominado por outra coisa, ou outro alguém?

\section{FORMOU O SENHOR DEUS O HOMEM}

Em narrativa do Gênesis, o homem teria sido criado do pó da terra e recebido da parte de Yahweh, o sopro de vida נֶפש nephesh - o que o tornaria a imagem e semelhança de seu criador. Uma essência do que representa. Não teria poder para realizar as mesmas coisas que o Criador faria, mas teria em si uma ligação essencial, que possibilitaria a auto consciência, a percepção do que há no mundo, e discernimento racional e espiritual. Certa percepção do que seriam limites e censuras, e do que seriam permissões e usufrutos. "O homem é uma imago dei, ele habita, tal como seu Criador e modelo, o paraíso". ${ }^{12}$

Em contra posição, as tradições mesopotâmias falariam de seres humanos criados à imagem de seus deuses. Geralmente, a imagem dos senhores e reis seriam erigidas em

\footnotetext{
11 WATSON, 2003, p. 28.

${ }^{12}$ ELIADE, 2010, p. 164.
}

Revista Pax Domini | Faculdade Boas Novas | v. 2 | p. 58 - 72 | mar. 2017 
forma de grandes obras e estátuas esculpidas para estabelecerem a autoridade, em determinada região. "Mas, no texto egípcio, as Instruções de Merikare, identifica a humanidade como formada por imagem de Deus, de cujo corpo se originaram". Sobre o mesmo texto egípcio, haveria coincidência com o texto hebraico, sobremodo que o homem seria formado por lágrimas dos deuses misturadas à argila, também com sopro de vida divino, no nariz do homem. O homem seria um ser com a essência divina, não um deus, mas colocado acima de toda a criação, inclusive para governá-la, com capacidades de auto consciência, e preceptoria. Isso se faria notar no momento em que a narrativa expressa sua procura por alguém que lhe fosse companheira de mesma espécie, desejada e pedida ao Criador. ${ }^{13}$

O fato de Eva ter sido criada de uma costela de Adão pode ser melhor esclarecido pelo conhecimento da língua suméria. A palavra suméria para costela é ti. É interessante saber que ti significa "vida", exatamente o mesmo significado de Eva. ${ }^{14}$

A essencialidade divina no homem, talvez não teria sido suficiente para tomar decisões que ocasionassem em benesses, como resultados de escolhas. O homem, mediante sua capacidade de percepção do que há no mundo, e discernimento racional e espiritual, desejaria ser igual ao Criador. Por outro lado, poderíamos refletir que a mensagem construto sacerdotal estaria arrolada a uma condição ideativa de obediência e devoção à Yahweh, com fins à manutenção de estrutura política e religiosa, utilizada em manutenção de monarquia. ${ }^{15}$

Não obstante, as intenções do texto em Gênesis, a intenção humana em se igualar aos deuses seriam proeminentes em alguns outros textos sobre mitos antigos, sendo que nestes, ser como Deus significaria em obter a vida eterna, enquanto que o texto hebreu, ser como Deus significaria ter a sabedoria do Criador. A ordem expressa que seria dada pelo próprio Deus, negaria o usufruto de apenas uma árvore, dentre todas as árvores do jardim, uma vez preparado para a moradia do homem, o que levaria ao homem a se perguntar o que aconteceria se esta orientação fosse desobedecida. ${ }^{16}$

\footnotetext{
${ }^{13}$ WATSON, 2003, p. 28-29.

14 Ibidem, p. 30.

15 KESSLER, Rainer. História social do antigo Israel. São Paulo: Paulinas, 2009, p. 91

${ }^{16}$ WATSON, 2003, p. 30-31.
}

Revista Pax Domini | Faculdade Boas Novas | v. 2 | p. 58 - 72 | mar. 2017 
O relato hebraico sobre a criação do homem não seria o único, no entanto, encantaria pela sua sistemática e senso situacional de desenvolvimento. Neste trabalho, sentimos atraído por incluir elementos de uma linguagem, que ao mesmo tempo em que se afastaria do discurso elaborado religioso, trazendo abordagem de forma científica, também seria influenciada por preceitos culturais de civilização judaico, romana, cristã. Ensaiamos a possibilidade de conjugarmos preceitos de um inventor e sua invenção, a fim de discutirmos a constituição humana. O pensamento de Sigmund Freud, o inventor da psicanálise ${ }^{17}$ de tradição judaica, traria certa base para refletirmos sob o episódio da queda do homem descrita no mito do Gênesis, como relação às hipóteses do que seria descrito como queda do homem, segundo os títulos utilizados nesta mesma narrativa canônica veterotestamentária.

Contudo, entendemos que seria interessante a abordagem feita pela linguagem psicanalítica da formação da mente humana. A conceituação teórica das tópicas do aparelho psíquico, que mencionariam o contato com a realidade de tudo o que há, no entanto, também como mecanismos organizados como obstáculos para total realização de nossos próprios desejos. Aliás, o desejo do homem relatado no Gênesis, ainda seria o mesmo desejo do homem atual?

\section{DA FORMAÇÃO PSÍQUICA DO HOMEM}

A narrativa da criação do homem atestaria o mecanismo do desejo, um dispositivo gerado no inconsciente, pulsionado através representações psíquicas e ideativas. ${ }^{18} \mathrm{O}$ desejo de ser dominador em vez de dominado, não seria de ordem endógena, no entanto, manifestaria o intento do homem na busca de gozo ao se sentir em pleno domínio da situação. Yahweh estaria retendo o homem de sua plena condição de liberdade. A possibilidade de que o homem, inconscientemente, desejaria o que Deus tem, ou seja, o poder irrestrito sobre tudo o que há, ficaria marcado na sua própria desobediência da orientação, uma vez posta, segundo a narrativa bíblica. Desta feita, e mente do primeiro homem poderia agregar os mesmos princípios localização do mecanismo psíquico, tal qual, oferecido pela teoria sobre as tópicas do aparelho psíquico freudiano.

\footnotetext{
${ }^{17}$ FREUD, Sigmund. Obras psicológicas completas de Sigmund Freud. Vol. XIV. Rio de Janeiro: Imago, 1996, p. 25-34.

${ }^{18}$ GARCIA-ROZA, Luis Alfredo. Freud e o inconsciente. Rio de Janeiro: Zahar, 2014, p. 77-86.
}

Revista Pax Domini | Faculdade Boas Novas | v. 2 | p. 58 - 72 | mar. 2017 
A estrutura do aparelho psíquico, segundo Freud, estaria desenvolvida de maneira em que o inconsciente, com atuação simbólica, responsável pela geração de desejos, sonhos, e pulsões de vida e de morte, teria desempenho arco reflexo, objetivando a realização de prazer, afirmando o desempenho do ld, uma fonte para toda necessidade de realizações de gozo. O pré-consciente, agregador de informes empíricos e de conteúdos mnêmicos, estaria posicionado entre 0 inconsciente e o consciente, responsável por agregar as leis e as regras, localizando-se o dispositivo do Superego, limitador, de censura e lei. O consciente estaria em contato direto com a realidade, posicionado para realizar decisões de forma mais racional, o que possibilitaria a Adão realizar a sua opção em plenas condições racionais, levando em conta as orientações emitidas pelo Superego e pelo Id. ${ }^{19}$ Por certo, Adão talvez não teria condições para entender a dimensão do resultado de sua decisão, mas o teria feito conscientemente, talvez embebido pelo desejo latente

Nesta estrutura, seria possível aferir que o mecanismo psíquico do primeiro homem agiria sob a performance do desejo, evocado pela capacidade de percepção do que há no mundo, e seu discernimento. Desejo de ter sabedoria, capacidade de criação, e total domínio sobre tudo o que há, tal qual Yahweh. O mecanismo superego seria acionado quando receberia a proibição de usufruir do fruto de uma das árvores do Jardim do Édem (Paraíso). Desta feita, seria oferecido ao ego consciente, certa decisão a ser tomada... A obediência às ordens e posicionamentos divinos, ou a aventura de dar vazão aos seus desejos, e descobrir resultado deste ato?

A decisão a ser tomada pelo primeiro homem, em narrativa do Gênesis, consistiria em manter a obediência à lei, ao superego, à censura, à versão, uma vez promulgada por Yaweh, ou burlar esta realidade a fim de atingir seu objetivo pulsional. A esta demanda que envolveria a pulsão de nutrição ${ }^{20}$ (ingestão de certa fruta envolvida), pulsões do saber $^{21}$ (sede de experimentar o desconhecido), a pulsão de dominação, ${ }^{22}$ e a pulsão

\footnotetext{
${ }^{19}$ FREUD, Sigmund. Obras psicológicas completas. O ego e o id e outros trabalhos. Vol. XIX. Rio de Janeiro: Imago, 1996, p. 27-54.

${ }^{20}$ FREUD, Sigmund. Um caso de histeria, três ensaios sobre sexualidade e outros trabalhos. Vol. VII. Rio de Janeiro: Imago, 1996, p. 184.

${ }^{21}$ FREUD, VII, 1996, p. 183.

22 Ibidem, p. 177.
}

Revista Pax Domini | Faculdade Boas Novas | v. 2 | p. 58 - 72 | mar. 2017 
sexual $^{23}$ (envolvente sedução por parte de Eva, e quiçá a serpente) seria classificada como perversão.

O termo derivado do latim pervertere (perverter), empregado em psiquiatria e pelos fundadores da sexologia, designa as práticas sexuais consideradas como desvios em relação a uma norma social e sexual. Seria a idéia de desvio sexual em relação a uma norma. Um fenômeno psíquico que juntamente com a psicose e a neurose, formaria a estrutura tripartite, segundo a escola de psicanálise francesa. O termo perversão abrangeria um campo muito mais amplo, na medida em que os comportamentos, as práticas e até as fantasias que engloba só poderiam ser apreendidos em relação a uma norma social que, por sua vez, induziria a uma norma jurídica. ${ }^{24}$

A narrativa mítica da criação judaica ofereceria algumas possibilidades de análise à luz da psicanálise, com relação aos conceitos de perversão. O homem e a mulher negariam a versão, uma vez oferecida. Então, a perversão teria origem na desobediência?

De acordo com as pesquisas freudianas, todos seríamos perversos polimorfos, e esta condição seria observada já na infância, pois crianças seriam os pequenos perversos polimorfos, ${ }^{25}$ que estariam em pleno exercício de descobertas e experimentos, uma vez que as fases infantis ainda construiriam o superego. Supõe-se que o primeiro casal estaria incluído nesta teoria, não apenas pelo fato de ser possível uma analogia da fase infantil com a as fases de conhecimento que o primeiro homem, provavelmente, teria passado, mas também porque a perversão poderia ser considerada como estrutura do ser humano, segundo a teoria lacaniana. ${ }^{26}$

Também em mesma teoria psíquica freudiana, o perverso entenderia a diferença sexual como castração real, brutal, e edipiana, ${ }^{27}$ mas seu psiquismo se recuaria a esta realidade, ocasionando a substituição do pênis. Desta feita, em narrativa da criação, a feminilidade fálica de Eva seria o real fruto proibido, ou a pulsão de saber adâmica? Seria o desejo por fazer morrer a vontade e onipotência de Yaweh, análogo ao preceitos edipianos? Ou ainda, Yaweh seria um fetiche?

\footnotetext{
${ }^{23}$ Ibidem, p. 172.

${ }^{24}$ DUNKER, Christian. A perversão nossa de cada dia. In: Revista Cult, Ano 13, n. 144, dossiê Perversão, Março, 2010, p. 42-46

${ }^{25}$ FREUD, VII, 1996, p. 180.

${ }^{26}$ LACAN, Jaques. Seminário 5 - a formação do inconsciente. Rio de Janeiro: Jorge Zahar, 1999.

${ }^{27}$ FREUD, 1996, p. 184.
}

Revista Pax Domini | Faculdade Boas Novas | v. 2 | p. 58 - 72 | mar. 2017 


\section{REPRESENTATIVIDADE DA QUEDA DO HOMEM}

Sobre a persuasão exterior, a hermêutica do texto hebraico nos traz um crítica com base nos relacionamentos antigos, entre o homem e a mulher, especificados pela sociedade daqueles tempos. Levando-se em consideração a autoria javista dos textos, e sua influencia patriarcalizada monárquica dos tempos de sua construção, a crítica hermenêutica do texto estaria voltada para o fato de que seria inadmissível a dominação da mulher sobre o marido, pois ambos teriam papéis definidos, que seriam prioritariamente controlados pelo homem. Uma análise do papel da mulher na queda da humanidade.

A formação da mulher a partir de uma costela retirada de Adão pode ser interpretada como indicadora da androginia do homem primordial. Concepções similares são atestadas em outras tradições, entre as quais as transmitida por algum midrashim". ${ }^{28}$

Algumas restrições foram dadas às mulheres, no entanto, teria seu papel no trabalho de familiar, mesmo que em período de gravidez e amamentação, fosse restringido. Mas, o homem teria sido persuadido pela mulher? E a mulher, teria sido persuadida pela serpente?

A persuasão do homem teria ocorrido pelo seu próprio desejo, e o nosso desejo é o desejo do outro. Se Yahweh desejaria ser respeitado e obedecido, então o desejo do primeiro homem incidiria em seu obedecido e respeitado, tanto quanto seu Criador. Para as análises freudianas do comportamento entre o pai e o filho, haveria uma condição narcísica infantil, de completa dependência das decisões do pai, tornando-se em fenômeno de psicastenia. ${ }^{29}$ De mesma forma, levando-se em conta este preceito, o primeiro homem, na verdade, descobre sua neurose infantilizada de dependência do Pai Yahweh, resolve se libertar de tal condição.

A mulher, sendo advinda do próprio homem, segundo as escrituras hebraicas, teria o mecanismo do aparelho psíquico semelhante, com desejos e pulsões, no entanto, com o agravante de ser a terceira no poder sobre a Criação. Seu desejo seria o desejo do

\footnotetext{
${ }^{28}$ WATSON, 2003, p. 32.

${ }^{29}$ SELL, Carlos Eduardo. BRÜSECKE, Franz Joseph. Mística e sociedade. Itajaí: Universidade do Vale de Itajaí; São Paulo: Paulinas, 2006, p. 24.
}

Revista Pax Domini | Faculdade Boas Novas | v. 2 | p. 58 - 72 | mar. 2017 
Outro, Adão e Yahweh. "Entretanto a serpente conseguiu tentar Eva [...] O dia em dele comerdes, vossos olhos se abrirão, e vós sereis como deuses [...] Temos em síntese, uma "imortalização" malograda". ${ }^{30}$ Seria um história de disputa entre amantes pela conquista da virgem carregada de culpa, vergonha e vulnerabilidades.

O desejo fálico de Eva poderia ser o real fruto proibido, pois o fato de ser castrada, em observação ao falo de Adão, segundo as perspectivas freudianas, Ihe traria a motivação pela busca de um recurso que pudesses oferecer uma substituição. Daí, o fruto proibido se tornaria o objeto fálico, de poder, que pudesse proporcionar a onisciência, portanto, a onipotência. Também alvo de fetiche "um substituto para o pênis", ${ }^{31}$ que na mente de Adão não teria motivação "justificável" para não estar lá. Hipoteticamente, teria supervalorizado o fruto que sua parceira adquiriu, burlando a censura divina, uma vez estipulada. Isso porque não queria ter a mesma sorte da própria Eva, ou seja, ser castrado em realidade.

A representação da serpente seria amplamente difundida na mitologia do Antigo Oriente Médio, com construções de templos tal como o santuário hitita da baixa idade do bronze, representado por um deus segurando uma serpente em uma mão e um bastão em outra. Na Babilônia do século XI a.C., um par de serpentes de bronze emoldurava cada uma das entradas do templo de Esagila. Os antigos mesopotâmicos e semitas acreditavam que a serpente era imortal por ser capaz de mudar de pele. "O papel da virgem, da árvore, da gruta, da serpente fálica como tentadora e tudo mais, são dados importados, com alguma modificação, da literatura pagã dos ritos da fertilidade". 32

Na proposta psicoteóloga de J. Harold Ellens (1986), o homem necessitaria passar por toda a questão da queda. O autor propõe que assim como todos os homens precisariam percorrer por estágios de vida, tais como, a infância, a adolescência, a juventude e a maturidade, o homem primeiro homem não seria poupado disto. Em situação metafórica dos estágios da vida humana, com a narrativa de Gênesis, em sua mais tenra idade, o homem seria totalmente dependente do seu Criador, por isso o obedeceria sem qualquer questionamento, e se submeteria ao primeiro comando de toda a criação. No segundo estágio da vida, o homem passaria a fase da adolescência, com

${ }^{30}$ ELIADE, 2010, p. 165-166.

${ }^{31}$ FREUD, Sigmund. O futuro de uma ilusão, o mal-estar na civilização e outros trabalhos. Vol. XXI.

Rio de Janeiro: Imago, 1996, p. 159.

${ }^{32}$ ELLENS, J. Harold. Psicoteologia. Aspectos básicos. São Leopoldo: Sinodal: 1986, p.18.

Revista Pax Domini | Faculdade Boas Novas | v. 2 | p. 58 - 72 | mar. 2017 
conflitos, questionamentos, e a busca pela ratificação de personalidade. Seria a época em que pensaria se realmente aconteceria o mal quando desobedecesse, ou seria apenas uma defesa de Yahweh quanto a possibilidade de divinização humana. Na fase jovem, que é quando precisaríamos assumir a responsabilidade e arcar com as consequências de nossas atitudes, o primeiro homem reconheceria a realidade de seus atos. $\mathrm{Na}$ fase mais madura, a humanidade se recordaria do tempo de infância, e de como seria mais fácil atentar para o que outros (os pais) ensinariam. ${ }^{33} \mathrm{O}$ primeiro homem lembraria das recomendações, e isso lhe evocaria o conteúdo mnêmico de satisfação de seus desejos. ${ }^{34}$

J. H. Ellens menciona que o homem precisaria passar por todo o episódio da queda, com a cumplicidade do Criador, para perceber sua dependência e necessidade de coexistência em submissão. ${ }^{35}$ Opção para responder a suposta cumplicidade de Yaweh Onisciente quanto à derrocada humana, sob nova realidade.

\section{SIGNIFICAÇÃO DO EXÍLIO}

Adão e Eva teriam que conviver com uma nova realidade, após o desafio mau sucedido. "E Deus pôs o casal para fora do paraíso e condenou-o a trabalhar para viver" (Gên. 3:23). Embora a história insistiria que toda a ansiedade e estresse humano seria decorrente o desejo de Adão ser igual a Deus e às "maldições" do trabalho com suor do rosto, das dores do parto para a mulher, e do comer pó e se rastejar para a serpente, e a saída imediata do jardim, que seria um paraíso, o homem seria alvo de certa ansiedade anterior.

No pensamento mesopotâmico, as pessoas foram criadas para serem escravas, devendo fazer o trabalho que os deuses estavam cansados de fazer, em grande parte relacional à agricultura [...] ao contrário do relato bíblico, no qual o homem foi criado para governar, recebendo o fardo do trabalho pesado com consequência da Queda. ${ }^{36}$

\footnotetext{
${ }^{33}$ Ibidem, p. 23-24.

${ }^{34}$ GARCIA-ROZA, 2014, p. 53.

35 ELLENS, 1986, p. 24.

${ }^{36}$ Ibidem, 2010, p. 166.
}

Revista Pax Domini | Faculdade Boas Novas | v. 2 | p. 58 - 72 | mar. 2017 
Adão teria a percepção de que estava só, em sua espécie, o que configuraria a necessidade por ter alguém semelhante, ao seu lado. No entanto, em episódio de conflito que marcaria a decisão de obedecer ou não as ordens do Criador, e a possibilidade do conhecimento do bem e do mal, tal qual Deus, fomentaria a intensificação conflituosa.

Alguns filósofos da religião diriam que as narrativas não poderiam comprometer a Deus por criar algo pesado, em demasia para que o homem respondesse. Tal afirmação seria uma incoerência, haja visto as propriedades de um Deus onisciente, onipresente, e onipotente, portanto, levando-se em consideração as prerrogativas deste Ser, tudo que faz, seria perfeito.

J. Ellens (1986) diz que o homem se acharia em pressão de responsabilidades, ao guardar o jardim, dar nomes aos animais, e ainda em desenvolver um relacionamento saudável com Eva. Talvez a perspectiva de não perder a atenção de Eva seria um dos motivos para desobediência a Deus, em troca da manutenção da relação de companheirismo. No entanto, a ansiedade humana não viria pelo fato do homem cometer o pecado, e sim porque seria um ser com potencial e possibilidades não exploradas. $O$ exílio seria uma nova oportunidade, uma mudança, muito mais do que uma sentença, uma possibilidade de novos desafios no processo de escolhas e decisões independentes. Uma oportunidade de retratar Deus como auxiliador, mas a responsabilidade de serem encarados os desafios da vida, pelo homem. ${ }^{37}$

\section{CONSIDERAÇÕES FINAIS}

Os mitos não possuem essência de engodo ou de meras histórias, antes tratam da explicação de fenômenos naturais e psíquicos, que de outro modo, não se fariam entendidos, pelo menos por um certo espaço de tempo. O mito da criação é um drama intenso de censura, desejo, castração, culpa e vergonha que revela a natureza essencial humana. A descrição da queda é um paradigma para o desenvolvimento psicológico, e as instância do aparelhamento psíquico humano em geral.

De acordo com a narrativa hebraica, haveria uma significativa ansiedade desenvolvida pelo homem, em relação a presença de uma árvore proibida, que poderia significar a possibilidade de ser igual a Deus, o que desvelaria a real condição essencial

${ }^{37}$ ELLENS, 1886, p. 28.

Revista Pax Domini | Faculdade Boas Novas | v. 2 | p. 58 - 72 | mar. 2017 
humana. Disto, a origem libidinal de onipotência, e a busca de ser igual a Yaweh, ou torná-lo um objeto de fetiche. A pressão desta ansiedade seria intensificada no conflito produzido pelo desafio da escolha, que resultaria no futuro de incerteza.

O homem se acharia em situação de responsabilidade de seus atos, não mais protegido ou poupado pelo Criador, mas ciente das consequências de suas opções. Obteria a liberdade, mas com esta, viria o peso da responsabilidade. Este peso ocasionaria a pressão da ansiedade inerente à natureza humana, agindo em um ser com plenos potenciais de crescimento e possibilidades não exploradas. Inclusive, a percepção de que a perversão faria parte de nossa estrutura, motivada pela pulsão do saber. A razão da questão polimorfa se daria pela infinidade de possibilidades empíricas a serem descobertas.

Vivendo o peso da paradoxal situação entre o saber, que traria um sentimento de potência fálica, e a castração por também entender a realidade de que quanto mais se sabe, mais precisa aprender, o primeiro homem havia sido castrado em seu desejo de domínio, com a censura referente ao fruto proibido. A relação com o Pai estaria comprometida, segundo os preceitos edipianos. O desejo da aniquilação do poder onipotente do Pai Criador teria motivado a burlar a censura, relacionando diretamente, o id com o ego, com o objetivo final de seu igual a Yaweh, Onipotente, detentor fálico.

Por outro lado, o desejo fálico de Eva poderia ser o real fruto proibido, pois o fato de ter sido castrada, em observação ao domínio de Adão, concederia motivações suficientes pela busca de recurso que pudesse oferecer uma substituição. Daí, o fruto proibido se tornaria o objeto fálico, de poder, que pudesse proporcionar a onisciência, portanto, a onipotência. Também alvo de fetiche, de supervalorização.

O fato é que a velha história mesopotâmica contada pelos hebreus com algumas variações, ajudaria a compreensão do processo de crescimento humano diante dos próprios dilemas e conflitos entre desejo e realidade.

\section{REFERENCIAS}

DUNKER, Christian. A perversão nossa de cada dia. In: Revista Cult, Ano 13, n. 144, dossiê Perversão, Março, 2010.

Revista Pax Domini | Faculdade Boas Novas | v. 2 | p. 58 - 72 | mar. 2017 
ELIADE, Mircea. História das crenças e das ideias religiosas I. Da idade da pedra aos ministérios de Elêusis. Rio de Janeiro: Zahar, 2010.

FREUD, Sigmund. Um caso de histeria, três ensaios sobre sexualidade e outros trabalhos. Vol. VII. Rio de Janeiro: Imago, 1996.

Obras psicológicas completas de Sigmund Freud. A história do movimento psicanalítico, artigos sobre a metapsicologia e outros trabalhos. Vol. XIV. Rio de Janeiro: Imago, 1996.

. Obras psicológicas completas. O ego e o id e outros trabalhos. Vol. XIX. Rio de Janeiro: Imago, 1996.

. O futuro de uma ilusão, o mal-estar na civilização e outros trabalhos. Vol. XXI. Rio de Janeiro: Imago, 1996.

GARCIA-ROZA, Luis Alfredo. Freud e o inconsciente. Rio de Janeiro: Zahar, 2014. KESSLER, Rainer. História social do antigo Israel. São Paulo: Paulinas, 2009. LACAN, Jaques. Seminário 5 - a formação do inconsciente. Rio de Janeiro: Jorge Zahar, 1999.

PURY, Albert (Org.). O Pentateuco em questão. As origens e a composição dos cinco primeiros livros da Bíblia à luz das pesquisas recentes. Petrópolis: Vozes, 2002. SELL, Carlos Eduardo. BRÜSECKE, Franz Joseph. Mística e sociedade. Itajaí: Universidade do Vale de Itajaí; São Paulo: Paulinas, 2006.

WALTON, Jonh H. Comentário bíblico de Atos. Antigo testamento. Belo Horizonte: Editora Atos, 2003.

Revista Pax Domini | Faculdade Boas Novas | v. 2 | p. 58 - 72 | mar. 2017 